\title{
Aplikasi Augmented Reality Pembelajaran Kerangka Manusia Berbasis Android
}

\author{
Alders Paliling'), Asrul Syam ${ }^{2)}$ \\ ${ }^{1,2}$ Teknik Informatika STMIK Dipanegara Makassar \\ Jl. Perintis Kemerdekaan Km.9, Makassar, 90123, Telp/Fax: 0411-587194 \\ E-mail: Alderspaliling@dipanegara.ac.id ${ }^{1)}, \underline{\text { com }}^{2)}$
}

\begin{abstract}
Abstrak
Salah satu materi yang diajarkan dalam matapelajaran IPA yaitu tentang kerangka manusia. Dalam proses pembelajaran kerangka manusia, guru menggunakan alat peraga berupa model kerangka manusia. Dengan perkembangan teknologi, penggunaan model kerangka manusia dapat digantikan dengan model digital. Model kerangka manusia dapat rusak baik dengan sengaja maupun dengan tidak sengaja dikarenakan termakan usia. Metode yang tepat untuk mengganti model kerangka manusia kedalam bentuk digital ialah dnegan menggunakan teknologi Augmented Reality, dimana teknologi Augmented Reality mampu memproyeksikan objek 3 dimensi kedalam dunia nyata seara langsung. penggunaan teknologi augmented reality kian marak digunakan dalam dunia pendidikan, kesehatan, penjualan, dan wisata. Hasil yang didapatkan pada penelitian ini ialah aplikasi dapat memproyeksikan objek 3 dimensi dari kerangka manusia yang dibagi menjadi 4 bagian yaitu tengkorak, tulang belakang dan tulang rusuk, tulang alat gerak atas dan tulang alat gerak bawah keatas marker. Berdasarkan pengujian yang telah dilakukan, maka disimpulkan bahwa jarak yang baik dalam mengidentifikasi marker antara smartphone dengan marker adalah pada jarak antara 2-6 inchi dan kemiringan marker terhadap smartphone adalah $0^{0}-60^{0}$.
\end{abstract}

Kata Kunci: Augmented Reality, Kerangka Manusia, IPA

\begin{abstract}
One of the materials taught in science lesson is about human skeletons. In the learning process of the human framework, teachers use props in the form of human skeletal models. With the development of technology, the use of human framework models can be replaced with digital models. Human skeletal models can be damaged either by deliberate or accidentally by age. The correct method for replacing the model of a human skeleton into a digital form is by using Augmented Reality technology, where Augmented Reality technology is capable of projecting 3-dimensional objects into the real world directly. the use of augmented reality technology is increasingly prevalent in the world of education, health, sales, and tourism. The results obtained in this study is the application can project 3-dimensional objects from the human skeleton that is divided into 4 parts of the skull, spine and ribs, the bone of the upper tool and the bone of the motion of the bottom of the marker. Based on the tests that have been done, it is concluded that a good distance in identifying markers between smartphones with markers is at a distance between 2-6 inches and marker slope of the smartphone is $0^{\circ}-60^{\circ}$.
\end{abstract}

Keywords: Augmented Reality, Human Skeletons, Science

\section{Pendahuluan}

Salah satu pokok pembahasan dalam mata pelajaran Biologi adalah pengenalan kerangka manusia. Dalam proses pembelajaran, guru menjelaskan menggunakan alat peraga. Alat peraga yang digunakan tentunya mempunyai kekurangan yaitu dapat rusak baik karna usia yang sudah tua, kerusakan akibat terjatuh dan lain sebagainya. Siswa hanya dapat belajar dengan menggunakan alat peraga disekolah, dan jika dirumah siswa tidak dapat menggunakan alat peraga dalam belajar. masalah ini dapat diatasi dengan mengganti alat peraga dengan aplikasi berbasis android yang menggunakan teknologi augmented reality. Teknologi augmented reality merupakan teknologi yang mapu menggabungkan dunia dua dimensi atau 
tiga dimensi dengan dunia nyata secara langsung [1]. Ada dua jenis metode augmented reality yaitu marker based dan markerless. Perbedaan mendasar anatara kedua tipe tersebut yaitu pada marker based memerlukan sebuah marker sebagai lokasi untuk menempatkan aset virtual, sedangkan marker less tidak membutuhkan marker namun membutuhkan GPS atau Compas [2].

Pemanfaatan teknologi augmneted reality dalam bidang pendidikan sudah banyak dikembangkan antara lain penggunaan teknologi augmented reality sebagai media pembelajaran hewan untuk anak usia dini dan pengenalan dinosaurus [3]. Pada penelitian tersebut, aplikasi yang dibangun mampu memproyeksikan objek tiga dimensi dari hewan ataupun dinosaurus kedalam dunia nyata hingga objek tiga dimensi tersebut nampak nyata berada didalam dunia nyata. Dalam bidang ilmu kimia penelitian yang pernah dilakukan yaitu tentang molekul. Pengguna dapat mengubah model molekul dua dimensi menjadi model molekul tiga dimensi yang dapat dimanipulasi [4]. Penelitian lain yang telah dilakukan dalam bidang ilmu kimia yaitu untuk menyelidiki bagaimana para siswa berinteraksi dengan augmented reality dan model fisik dan mengevaluasi persepsi siswa mengenai dua epresentasi dalam belajar tentang asam amino [5]. Dalam dunia perdagangan, augmented reality juga sering digunakan sebagai media promosi penjualan seperti penelitian yang telah dilakukan sebelumnya dimana aplikasi dapat memproyeksikan objek tiga dimensi rumah yang sedang dipasarkan, sehingga pengguna dapat melihat bentuk rumah dari berbagai sisi[6].

Peneitian tentang pengembangan media pembelajaran kerangka manusia dilakukan oleh Reynoldus Andrias Sahulata dkk, dimana model 3D kerangka manusia ditampilkan kelayar smartphone [7]. Penelitian tersebut menggunakan teknologi Virtual Reality, dimana pengguna dibawa kedalam dunia virtual. Media pembelajaran berbasis multimedia dapat berpengaruh terhadap tingkat pemahaman siswa terhadap materi, dapat meningkatkan keaktifan, kreativitas bagi siswa dan guru [8]

Pengembangan media pembelajaran macromedia flash pada mata pelajaran fisika submateri perpindahan kalor memberikan pengaruh positif terhadap prestasi belajar siswa, sehingga media ini dikatakan memiliki kriteria baik[9].

Penelitian ini bertujuan untuk membangun sebuah perangkat lunak yang beroperasi pada smart phone bersistem operasi android. Aplikasi yang dibangun membutuhkan kamera yang ada pada smart phone untuk mengidentifikasi marker. Pengguna cukup mengarahkan kamera kearah marker dan aplikasi akan mengidentifikasi marker, jika marker teridentifikasi, maka objek tiga dimensi dari kerangka manusia akan ditampilkan.

\section{Metodologi Penelitian}

Dalam penelitian ini dilakukukan beberapa tahapan antara lain analisis sistem, desain sistem dan implementasi.

\subsection{Analisis Sistem}

Dalam proses analisis dikumpulkan beberapa data pendukung penelitian, data-data tersebut berupa model kerangka manusia yang nantiya dibentuk dalam model 3D yang nantinya ditampilkan diatas marker, dan dibentuk dalam model 2D yang dijadikan marker. Adapun kerangka manusia yang digunakan adalah, tengkorak, tulang dada, tulang alat gerak atas, tulang alat gerak bawah.

\subsection{Desain Sistem}

Desain sistem dilakukan untuk memudahkan proses pembuatan sistem, dimana alur pembuatan sistem, arsitektur sistem dijelaskan dalam desain sistem. Berikut gambar alur pembuatan sistem 


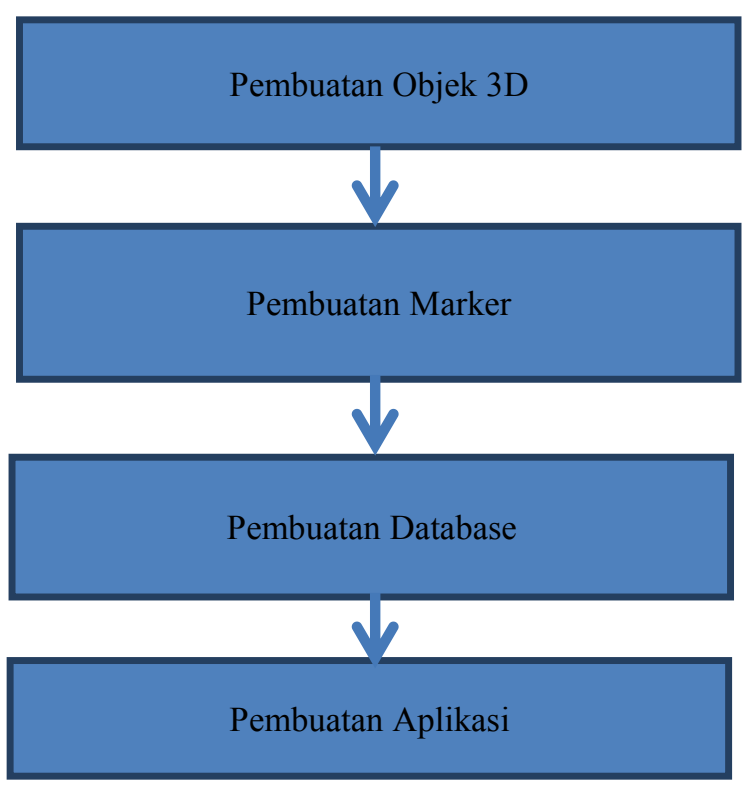

Gambar 1 Desain Sistem

Pembuatan objek 3D dilakukan menggunakan Software Blender, pembuatan marker dilakukan menggunakan Software Adobe Photoshop, pembuatan database dilakukan di www.vuforia.com, pembuatan aplikasi dilakukan menggunakan software Unity 3D.

Selajutnya adalah pembuatan arsitektur sistem diamna arsitektur menjelaskan cara kerja sistem yang akan dirancang. Berikut gambar arsitektur sistem :

\section{Gambar 2 Arsitektur}

Gambar diatas

aplikasi yang dirancang

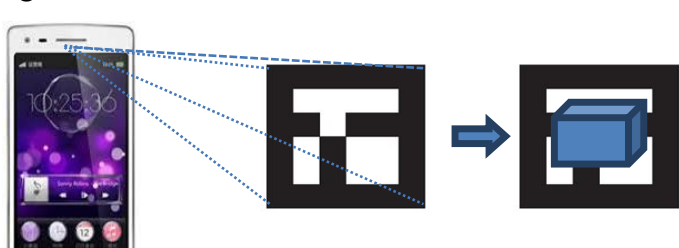

\section{Sistem}

menjelaskan bahawa membutuhkan kamera

yang terdapat pada smart phone, ketika kamera diarahkan kearah amrker dan marker berhasil diidentifikasi, maka objek 3D akan ditampilkan diatas marker.

\subsection{Implementasi Sistem}

Pada tahapan ini merupakan tahapan implementasi dari desain sistem dimana dimulai dari pembuatan objek 3D. berikut adalah hasil pembuatan objek 3D kerangka manusia

\section{Objek 3D Tengkorak}

Objek 3D tengkorak yang dibuat nantinya titampilkan diatas marker ketika aplikasi berhasil mengidentifikasi marker_a. Berikut gambar objek 3D tengkorak

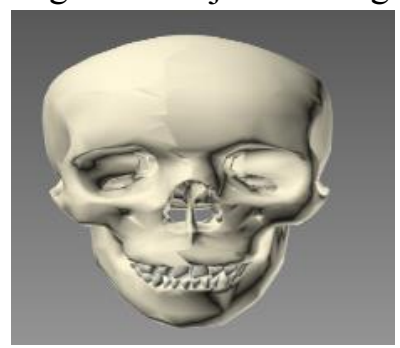

Gambar 3 Objek 3D Tengkorak 
2. Objek 3D Tulang Dada

Objek 3D tulang dada yang dibuat nantinya titampilkan diatas marker ketika aplikasi berhasil mengidentifikasi marker_b. Berikut gambar objek 3D tulang dada

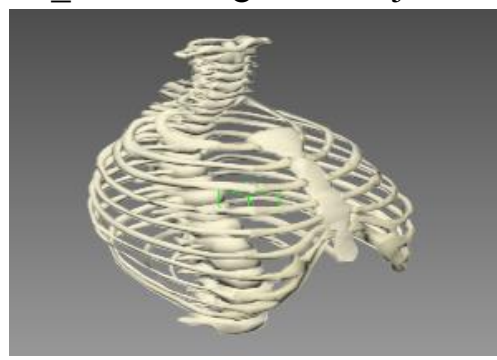

Gambar 4 Objek 3D Tulang Dada

3. Objek 3D tulang alat gerak atas

Objek 3D tulang alat gerak atas yang dibuat nantinya titampilkan diatas marker ketika aplikasi berhasil mengidentifikasi marker_c. Berikut gambar objek 3D tulang alat gerak atas

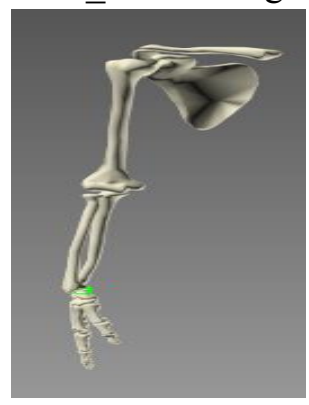

Gambar 5 Objek 3D Tulang alat Gerak Atas

4. Objek 3D tulang alat gerak bawah

Objek 3D tulang alat gerak bawah yang dibuat nantinya titampilkan diatas marker ketika aplikasi berhasil mengidentifikasi marker_d. Berikut gambar objek 3D tulang alat gerak bawah

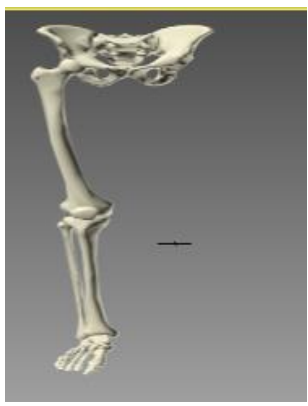

Gambar 6 Objek 3D Tulang alat Gerak Atas

Setelah dilakukan pembuatan Objek 3D, maka selanjutnya dilakukan pembuatan marker. Pada penelitan ini menggunakan 4 buah marker dimana marker tersebut mewakili empat bagian. Adapun marker yang digunakan yaitu marker_a yang berfungsi sebagai penanda objek tiga dimensi Tengkorak, marker_b yang berfungsi sebagai penanda objek tiga dimensi tulang belakang dan rusuk, marker_c yang berrfungi sebagai penanda untuk objek tiga dimensi tulang alat gerak atas, dan marker_d sebagai penanda objek tiga dimensi tulang alat gerak bawah. Berikut adalah gambar merker yang digunakan

1. Marker_a

Adapun gambar marker_a dapat dilihat pada gambar dibawah ini : 


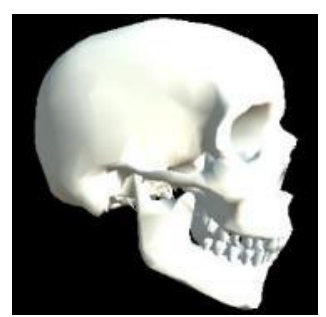

Gambar 7 Marker a

Ketika marker_a teridentifikasi oleh aplikasi, maka aplikasi akan memproyeksikan objek tiga dimensi dari tengkorak di atas marker dan jika marker_a dikeluarkan dari jangkauan kamera, maka objek tiga dimensi tengkorak akan hilang dari marker.

2. Marker_b

Adapun gambar marker_b dapat dilihat pada gambar dibawah ini :

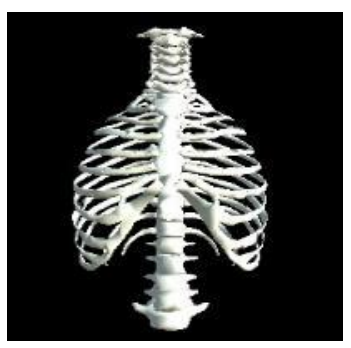

Gambar 8 marker b

Ketika marker_b teridentifikasi oleh aplikasi, maka aplikasi akan memproyeksikan objek tiga dimensi dari tulang belakang dan rusuk di atas marker dan jika marker_b dikeluarkan dari jangkauan kamera, maka objek tiga dimensi tulang belakang dan rusuk akan hilang dari marker.

3. Marker_c

Adapun gambar marker_c dapat dilihat pada gambar dibawah ini :

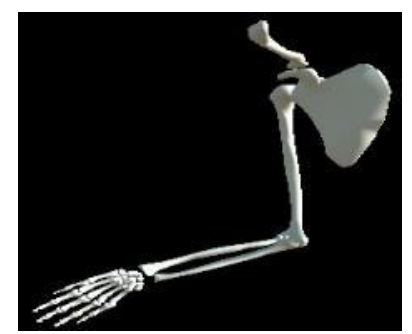

Gambar 9 marker_c

Ketika marker_c teridentifikasi oleh aplikasi, maka aplikasi akan memproyeksikan objek tiga dimensi dari tulang alat gerak atas di atas marker dan jika marker_c dikeluarkan dari jangkauan kamera, maka objek tiga dimensi tulang tulang alat gerak atas akan hilang dari marker.

4. Marker_d

Adapun gambar marker_d dapat dilihat pada gambar dibawah ini : 


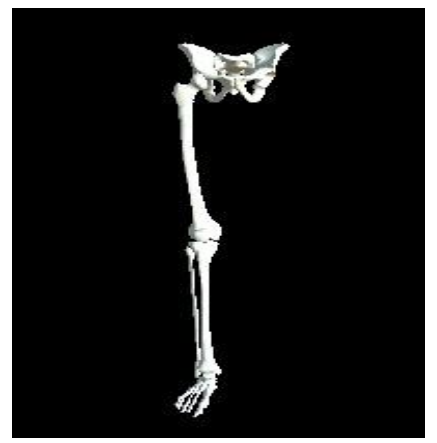

Gambar 10 marker_d

Ketika marker_d teridentifikasi oleh aplikasi, maka aplikasi akan memproyeksikan objek tiga dimensi dari tulang alat bawah atas di atas marker dan jika marker_d dikeluarkan dari jangkauan kamera, maka objek tiga dimensi tulang tulang alat gerak bawah akan hilang dari marker.

\section{HASIL DAN PEMBAHASAN}

Penelitian ini menghasilkan sebuah perangkat lunak berbasis android yang memanfaatkan teknologi augmented reality dengan metode marker based. Pada penelitian ini, digunakan tools unity sebagai editor, $\mathrm{C \#}$ sebagai bahasa pemrograman, dan Vuforia SDK sebagai library augmented reality. Adapun hasil dari penelitian ini yaitu :

1. Tampilan hasil scan marker_a

Ketika aplikasi berhasil mengenali pola marker a, maka aplikasi akan memproyeksikan objek tiga dimensi tengkorak diatas marker. Berikut adalah gambar tampilan ketika objek tiga dimensi tengkorak diproyeksikan diatas marker_a

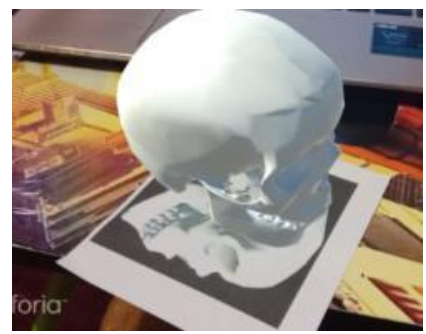

Gambar 11 Tampilan hasil scan marker_a

2. Tampilan hasil scan marker_b

Ketika aplikasi berhasil mengenali pola marker_b, maka aplikasi akan memproyeksikan objek tiga dimensi tulang belakang dan rusuk diatas marker. Berikut adalah gambar tampilan ketika objek tiga dimensi tulang belakang dan rusuk diproyeksikan diatas marker_b

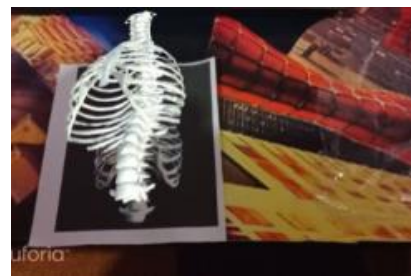

Gambar 12 Tampilan hasil scan marker_b 
3. Tampilan hasil scan marker_c

Ketika aplikasi berhasil mengenali pola marker_c, maka aplikasi akan memproyeksikan objek tiga dimensi tulang alat gerak atas diatas marker. Berikut adalah gambar tampilan ketikaobjek tiga dimensi tulang alat gerak atas diproyeksikan diatas marker_c

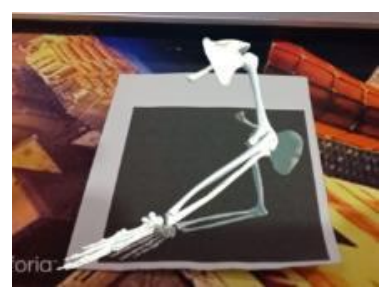

Gambar 13 Tampilan hasil scan marker_c

4. Tampilan hasil scan marker_d

Ketika aplikasi berhasil mengenali pola marker_d, maka aplikasi akan memproyeksikan objek tiga dimensi tulang alat bawah atas diatas marker. Berikut adalah gambar tampilan ketikaobjek tiga dimensi tulang alat gerak bawah diproyeksikan diatas marker_d.

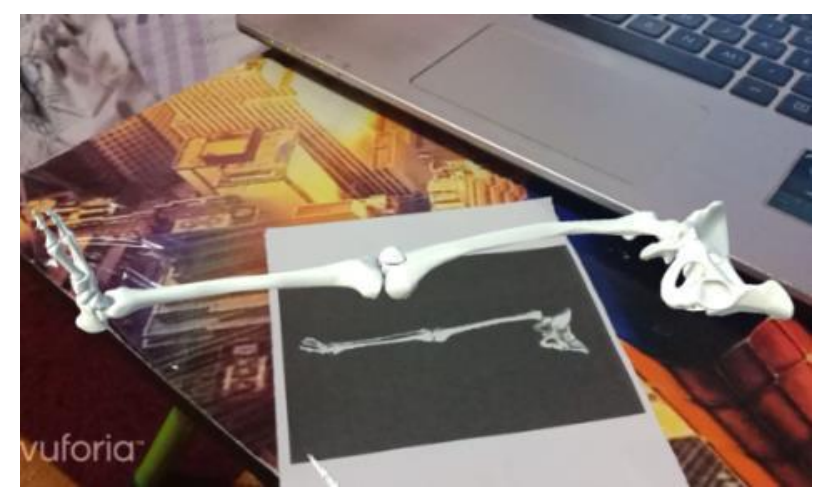

\subsection{Pengujian}

Gambar 14 Tampilan hasil scan marker_d

Setelah perancangan dan pembuatan aplikasi, maka selanjutnya dilakukan pengujian terhadap aplikasi yang telah dibangun. Pengujian yang pertama dilakukan adalah pengujian terhadap jarah marker dengan smartphone. Adapun hasil pengujian yang telah dilakukan dapat dilihat pada tabel dibawah ini :

Tabel 1 Hasil Pengujian jarak marker a

\begin{tabular}{ccc}
\hline No & Jarak(Inc) & Hasil \\
\hline $\mathbf{1}$ & 1 & Objek tiga dimensi Tidak Tampil \\
$\mathbf{2}$ & 2 & Objek tiga dimensi Tidak Tampil \\
$\mathbf{3}$ & 3 & Objek tiga dimensi Tampil \\
$\mathbf{4}$ & 4 & Objek tiga dimensi Tampil \\
$\mathbf{5}$ & 5 & Objek tiga dimensi Tampil \\
$\mathbf{6}$ & 6 & Objek tiga dimensi Tidak Tampil \\
\hline
\end{tabular}




\begin{tabular}{ccc}
\hline No & Jarak(Inc) & Hasil \\
\hline $\mathbf{7}$ & 7 & Objek tiga dimensi Tidak Tampil \\
$\mathbf{8}$ & 8 & Objek tiga dimensi Tidak Tampil \\
$\mathbf{9}$ & 9 & Objek tiga dimensi Tidak Tampil \\
$\mathbf{1 0}$ & 10 & Objek tiga dimensi Tidak Tampil \\
\hline
\end{tabular}

Pada pengujian jarak marker_a, didapatkan bahwa pada jarak 1 dan 2 Inc objek tiga dimensi tidak tampil yang artinya bahwa aplikasi tidak dapat mengidentifikasi marker_a. pada jarak 3,4,5 Inc objek tiga dimensi tampil yang artinya bahwa aplikasi berhasil mengidenifikasi marker_a. pada jarak 6,7,8,9,10 objek tiga dimensi tidak tampil yang artinya aplikasi tidak dapat mengidentifikasi marker.

Tabel 2 Hasil Pengujian jarak marker $b$

\begin{tabular}{lcc}
\hline No & Jarak(Inc) & Hasil \\
\hline $\mathbf{1}$ & 1 & Objek tiga dimensi Tidak Tampil \\
$\mathbf{2}$ & 2 & Objek tiga dimensi Tampil \\
$\mathbf{3}$ & 3 & Objek tiga dimensi Tampil \\
$\mathbf{4}$ & 4 & Objek tiga dimensi Tampil \\
$\mathbf{5}$ & 5 & Objek tiga dimensi Tampil \\
$\mathbf{6}$ & 6 & Objek tiga dimensi Tampil \\
$\mathbf{7}$ & 7 & Objek tiga dimensi Tampil \\
$\mathbf{8}$ & 8 & Objek tiga dimensi Tidak Tampil \\
$\mathbf{9}$ & 9 & Objek tiga dimensi Tidak Tampil \\
$\mathbf{1 0}$ & 10 & Objek tiga dimensi Tidak Tampil \\
\hline
\end{tabular}

Pada pengujian jarak marker $b$, didapatkan bahwa pada jarak 1 Inc objek tiga dimensi tidak tampil yang artinya bahwa aplikasi tidak dapat mengidentifikasi marker_b. pada jarak 2,3,4,5,6,7 Inc objek tiga dimensi tampil yang artinya bahwa aplikasi berhasil mengidenifikasi marker_b. pada jarak 8,9,10 objek tiga dimensi tidak tampil yang artinya aplikasi tidak dapat mengidentifikasi marker.

Tabel 3 Hasil Pengujian jarak marker c

\begin{tabular}{ccc}
\hline No & Jarak(Inc) & Hasil \\
\hline $\mathbf{1}$ & 1 & Objek tiga dimensi Tidak Tampil \\
$\mathbf{2}$ & 2 & Objek tiga dimensi Tampil \\
$\mathbf{3}$ & 3 & Objek tiga dimensi Tampil \\
\hline
\end{tabular}




\begin{tabular}{ccc}
\hline No & Jarak(Inc) & Hasil \\
\hline $\mathbf{4}$ & 4 & Objek tiga dimensi Tampil \\
$\mathbf{5}$ & 5 & Objek tiga dimensi Tampil \\
$\mathbf{6}$ & 6 & Objek tiga dimensi Tidak Tampil \\
$\mathbf{7}$ & 7 & Objek tiga dimensi Tidak Tampil \\
$\mathbf{8}$ & 8 & Objek tiga dimensi Tidak Tampil \\
$\mathbf{9}$ & 9 & Objek tiga dimensi Tidak Tampil \\
$\mathbf{1 0}$ & 10 & Objek tiga dimensi Tidak Tampil \\
\hline
\end{tabular}

Pada pengujian jarak marker_c, didapatkan bahwa pada jarak 1 Inc objek tiga dimensi tidak tampil yang artinya bahwa aplikasi tidak dapat mengidentifikasi marker_c. pada jarak 2,3,4,5 Inc objek tiga dimensi tampil yang artinya bahwa aplikasi berhasil mengidenifikasi marker_c. pada jarak $6,7,8,9,10$ objek tiga dimensi tidak tampil yang artinya aplikasi tidak dapat mengidentifikasi marker.

Tabel 4 Hasil Pengujian jarak marker d

\begin{tabular}{lcc}
\hline No & Jarak(Inc) & Hasil \\
\hline $\mathbf{1}$ & 1 & Objek tiga dimensi Tidak Tampil \\
$\mathbf{2}$ & 2 & Objek tiga dimensi Tampil \\
$\mathbf{3}$ & 3 & Objek tiga dimensi Tampil \\
$\mathbf{4}$ & 4 & Objek tiga dimensi Tampil \\
$\mathbf{5}$ & 5 & Objek tiga dimensi Tampil \\
$\mathbf{6}$ & 6 & Objek tiga dimensi Tampil \\
$\mathbf{7}$ & 7 & Objek tiga dimensi Tidak Tampil \\
$\mathbf{8}$ & 8 & Objek tiga dimensi Tidak Tampil \\
$\mathbf{9}$ & 9 & Objek tiga dimensi Tidak Tampil \\
$\mathbf{1 0}$ & 10 & Objek tiga dimensi Tidak Tampil \\
\hline
\end{tabular}

Pada pengujian jarak marker_d, didapatkan bahwa pada jarak 1 Inc objek tiga dimensi tidak tampil yang artinya bahwa aplikasi tidak dapat mengidentifikasi marker_d. pada jarak 2,3,4,5,6 Inc objek tiga dimensi tampil yang artinya bahwa aplikasi berhasil mengidenifikasi marker_d. pada jarak 7,8,9,10 objek tiga dimensi tidak tampil yang artinya aplikasi tidak dapat mengidentifikasi marker.

Selanjutnya adalah pengujian kemiringan marker terhadap smartphone. Pengaujian dilakukan untuk mengetahui kemampuan aplikasi dalam mengidentifikasi marker dalam posisi miring. Jarak antara marker dengan kamera yaitu 6 inc. Berikut adalah hasil pengujian kemiringan marker. 
Tabel 5 Hasil Pengujian kemiringan marker a

\begin{tabular}{lcc}
\hline No & Kemiringan $\left({ }^{0}\right)$ & Hasil \\
\hline $\mathbf{1}$ & 5 & Objek tiga dimensi Tampil \\
$\mathbf{2}$ & 10 & Objek tiga dimensi Tampil \\
$\mathbf{3}$ & 20 & Objek tiga dimensi Tampil \\
$\mathbf{4}$ & 30 & Objek tiga dimensi Tampil \\
$\mathbf{5}$ & 40 & Objek tiga dimensi Tampil \\
$\mathbf{6}$ & 50 & Objek tiga dimensi Tampil \\
$\mathbf{7}$ & 60 & Objek tiga dimensi Tampil \\
$\mathbf{8}$ & 70 & Objek tiga dimensi Tidak Tampil \\
$\mathbf{9}$ & 80 & Objek tiga dimensi Tidak Tampil \\
$\mathbf{1 0}$ & 90 & Objek tiga dimensi Tidak Tampil \\
\hline
\end{tabular}

Pada pengujian Kemiringan marker_a, didapatkan bahwa pada kemirinagn $5^{0}-60^{0}$ objek tiga dimensi tampil yang artinya bahwa aplikasi dapat mengidentifikasi marker_a. pada kemiringan $70^{\circ}-90^{\circ}$ objek tiga dimensi tiadak tampil yang artinya bahwa aplikasi tidak berhasil mengidenifikasi marker_a.

Tabel 6 Hasil Pengujian kemiringan marker $b$

\begin{tabular}{lcc}
\hline No & Kemiringan $\left({ }^{0}\right)$ & Hasil \\
\hline $\mathbf{1}$ & 5 & Objek tiga dimensi Tampil \\
$\mathbf{2}$ & 10 & Objek tiga dimensi Tampil \\
$\mathbf{3}$ & 20 & Objek tiga dimensi Tampil \\
$\mathbf{4}$ & 30 & Objek tiga dimensi Tampil \\
$\mathbf{5}$ & 40 & Objek tiga dimensi Tampil \\
$\mathbf{6}$ & 50 & Objek tiga dimensi Tampil \\
$\mathbf{7}$ & 60 & Objek tiga dimensi Tampil \\
$\mathbf{8}$ & 70 & Objek tiga dimensi Tidak Tampil \\
$\mathbf{9}$ & 80 & Objek tiga dimensi Tidak Tampil \\
$\mathbf{1 0}$ & 90 & Objek tiga dimensi Tidak Tampil \\
\hline
\end{tabular}

Pada pengujian Kemiringan marker_b, didapatkan bahwa pada kemirinagn $5^{0}-60^{0}$ objek tiga dimensi tampil yang artinya bahwa aplikasi dapat mengidentifikasi marker_b. pada kemiringan $70^{\circ}-90^{0}$ objek tiga dimensi tiadak tampil yang artinya bahwa aplikasi tidak berhasil mengidenifikasi marker_b.

Tabel 7 Hasil Pengujian kemiringan marker_c 


\begin{tabular}{|c|c|c|}
\hline No & Kemiringan $\left({ }^{0}\right)$ & Hasil \\
\hline 1 & 5 & Objek tiga dimensi Tampil \\
\hline 2 & 10 & Objek tiga dimensi Tampil \\
\hline 3 & 20 & Objek tiga dimensi Tampil \\
\hline 4 & 30 & Objek tiga dimensi Tampil \\
\hline 5 & 40 & Objek tiga dimensi Tampil \\
\hline 6 & 50 & Objek tiga dimensi Tidak Tampil \\
\hline 7 & 60 & Objek tiga dimensi Tidak Tampil \\
\hline 8 & 70 & Objek tiga dimensi Tidak Tampil \\
\hline 9 & 80 & Objek tiga dimensi Tidak Tampil \\
\hline 10 & 90 & Objek tiga dimensi Tidak Tampil \\
\hline \multicolumn{3}{|c|}{$\begin{array}{l}\text { Pada pengujian Kemiringan marker_c, didapatkan bahwa pada kemirinagn } 5^{0}-40^{0} \text { objek tiga } \\
\text { dimensi tampil yang artinya bahwa aplikasi dapat mengidentifikasi marker_a. pada kemiringan } 50^{0}-90^{0} \\
\text { objek tiga dimensi tiadak tampil yang artinya bahwa aplikasi tidak berhasil mengidenifikasi marker_c. } \\
\text { Tabel } 8 \text { Hasil Pengujian kemiringan marker_d }\end{array}$} \\
\hline No & Kemiringan $\left({ }^{0}\right)$ & Hasil \\
\hline 1 & 5 & Objek tiga dimensi Tampil \\
\hline 2 & 10 & Objek tiga dimensi Tampil \\
\hline 3 & 20 & Objek tiga dimensi Tampil \\
\hline 4 & 30 & Objek tiga dimensi Tampil \\
\hline 5 & 40 & Objek tiga dimensi Tampil \\
\hline 6 & 50 & Objek tiga dimensi Tampil \\
\hline 7 & 60 & Objek tiga dimensi Tidak Tampil \\
\hline 8 & 70 & Objek tiga dimensi Tidak Tampil \\
\hline 9 & 80 & Objek tiga dimensi Tidak Tampil \\
\hline 10 & 90 & Objek tiga dimensi Tidak Tampil \\
\hline
\end{tabular}

Pada pengujian Kemiringan marker_d, didapatkan bahwa pada kemirinagn $5^{0}-50^{0}$ objek tiga dimensi tampil yang artinya bahwa aplikasi dapat mengidentifikasi marker_a. pada kemiringan $60^{\circ}-90^{\circ}$ objek tiga dimensi tiadak tampil yang artinya bahwa aplikasi tidak berhasil mengidenifikasi marker_c. 


\section{KESIMPULAN}

Pada penelitian ini aplikasi dapat memproyeksikan objek 3 dimensi dari kerangka manusia yang tebagi menjadi 4 bagian sesuai dengan amrker masing-masing. Berdadarkan hasil pengujian yang dilakukan, maka disimpulkan bahwa jarak antara marker dan smartphone yang baik dalam proses mengidentifikasi marker adalah di jarak antara 2 sampai 6 Inc. jika jarak kamera terhadap marker terlalu dekat ataupun terlalu jauh, maka marker tidak dapat teridentifikasi.

\section{UCAPAN TERIMA KASIH}

Terima kasih kepada Dipa Ristek Dikti yang telah memberikan pendanaan untuk penelitian ini.

\section{DAFTAR PUSTAKA}

[1] Azuma, R. T. (1997). A survey of augmented reality. Presence: Teleoperators \& Virtual Environments, 6(4), 355-385.

[2] Katiyar, A., Kalra, K., \& Garg, C. (2015). Marker based augmented reality. Advances in Computer Science and Information Technology (ACSIT), 2(5), 441-445.

[3] Paliling, A., \& Rusdi, W. (2018, February). Pemanfaatan Teknologi Augmented Reality dalam Aplikasi Pengenalan Hewan untuk Anak Usia Dini berbasis Android. In SISITI: Seminar Ilmiah Sistem Informasi dan Teknologi Informasi (Vol. 7, No. 1).

[4] Behmke, D., Kerven, D., Lutz, R., Paredes, J., Pennington, R., Brannock, E., ... \& Stevens, K. (2018). Augmented Reality Chemistry: Transforming 2-D Molecular Representations into Interactive 3-D Structures. In Proceedings of the Interdisciplinary STEM Teaching and Learning Conference (Vol. 2, No. 1, pp. 4-12).

[5] Chen, Y. C. (2006, June). A study of comparing the use of augmented reality and physical models in chemistry education. In Proceedings of the 2006 ACM international conference on Virtual reality continuum and its applications (pp. 369-372). ACM.

[6] Paliling, A. (2017). Katalog Penjualan Rumah Berbasis Android Menggunakan Teknologi Augmented Reality dan Virtual Reality. Techno. Com, 16(1), 35-46.

[7] Sahulata, R. A., Wahyudi, A., Wuwungan, B. G., \& Nayoan, M. A. (2016). Aplikasi Virtual Reality Pengenalan Kerangka Tubuh Manusia Berbasis Android. Cogito Smart Journal, 2(2), 204-215.

[8] Intan, I.(2014), Enhacement Of Quality Of Learning Through Material Presentation Based On Multimedia In Barrang Lompo Island (Peningkatan Kualitas Pembelajaran melalui Penyajian Materi Berbasis Multimedia di Pulau Barrang Lompo). Pekommas, 1(2), 121-132.

[9] Arafiana, R. N. (2014). Penerapan Pembelajaran Gerak Lurus dengan Media Pembelajaran Macromedia Flash dalam Menyajikan Grafik untuk Meningkatkan Hasil Belajar Fisika Siswa di SMPN 3 Nganjuk. Inovasi Pendidikan Fisika, 3(2). 